\title{
The Effect of the Empowerment Program on the Chronic Sorrow of the Parents of Premature Newborn in Neonatal Intensive Care Units
}

\author{
Hamid Moradi ${ }^{1}$, Leili Borimnejad ${ }^{2}$, Nayimeh Seyed Fatemi ${ }^{3}$, \\ Hamid Haghani ${ }^{4}$, Mojgan Moradi ${ }^{5}$
}

\begin{abstract}
Background \& Aims: Sorrow is a natural response to adverse events such as loss and birth of premature or abnormal neonates, which increases the risk of chronic physical diseases, substance abuse, and suicide if prolonged. In addition, sorrow decreases the quality of life of individuals, causing variable degrees of disability in individual and social functions. The components of chronic sorrow in the parents of premature neonates include premature birth, developmental disabilities, Down syndrome, neural tube defects (e.g., meningococcus), and chronic diseases (e.g., cancer). The parents of these neonates experience variable degrees of chronic sorrow, which in turn makes it difficult to care for and interact with the newborn. The birth of a premature neonate is the main challenge in postpartum care. In general, approximately 13 million births lead to premature birth each year. Iran has one of the highest prevalence rates of premature birth across the world, where 5,000 neonates are born daily, $12 \%$ of whom are underweight and 10-15\% are born premature before 37 weeks of gestation. The birth of a newborn that needs special care causes psychologically special and shocking conditions for the parents, preventing the fulfillment of their true role as a parent. Sorrow occurs when parents find out that their newborn is 'incomplete'. Sorrow encompasses both internal phenomena (e.g., thoughts and feelings) and external phenomena in the form of behaviors related to sorrow (e.g., sadness and crying). One of the main nursing interventions in this regard involves diminishing the problems of the parents whose newborn is hospitalized in the intensive care unit through their empowerment by providing the required knowledge for the better care of admitted premature neonates, which has been highlighted within the context of family-oriented care to increase the quality of life of the neonate and families. In general, the implementation of proper nursing interventions could lead to positive outcomes for parents, reducing issues such as grief, stress, changed parental roles as a major nursing measure for diminishing the problems of the parents whose neonates are admitted to the neonatal intensive care unit. The empowerment of parents occurs by providing the necessary conditions for the interaction and participation of parents in the care of premature neonates. The creating opportunities for parent empowerment (COPE) was designed by Melnyk et al. in 2001 for the parents of premature infants. COPE is a four-stage educational-behavioral intervention based on the self-regulatory and control theories. In addition to the mental support of parents, this program provides the necessary information regarding the complexion and behaviors of premature infants, parental roles, conditions of the intensive care unit, and proper care of the neonates. The present study aimed to assess the effects of the COPE on the chronic sorrow of the parents of the premature neonates admitted to the neonatal intensive care unit (NICU).

Materials \& Methods: This non-randomized clinical trial was conducted with a control group after the approval of the research plan and obtaining the required permit from the Ethics Committee and an introduction letter from Iran University of Medical Sciences at NICUs of Rasoul Akram and Ali Asghar hospitals in Tehran,
\end{abstract}

1. MS in Neonatal Intensive Care Nursing, School of Nursing and Midwifery, Iran University of Medical Sciences, Tehran, Iran

2. Professor, Nursing Care Research Center, School of Nursing and Midwifery, Iran University of Medical Sciences, Tehran, Iran (Corresponding author) Tel: $88201978 \quad$ Email: borimnejad.l@iums.ac.ir

3. Professor, Nursing Care Research Center, School of Nursing and Midwifery, Iran University of Medical Sciences, Tehran, Iran

4. Instructor, Department of Biostatistics, School of Health, Iran University of Medical Sciences, Tehran, Iran

5. MS in Medical-Surgical Nursing, School of Nursing and Midwifery, Iran University of Medical Sciences, Tehran, Iran 
Iran. Based on the inclusion criteria, 68 parents with premature infants admitted to the NICU were selected via convenience sampling. The stratification of the subjects to two groups was based on a time framework. Initially, the control group was samples, followed by the sampling of the intervention group. Data were collected using a demographic questionnaire and Kendall chronic sorrow instrument with 18 items scored based on a Likert scale, which were collected by the subjects in both groups. In the intervention group, the COPE program (four-stage educational-behavioral intervention) was carried out, and the control group received the routine care of the ward. The trainings and meetings with the parents were performed in groups of 2-4, including the mother and father, in the conference room of the ward with the permission of the head nurse by the researcher and the coresearcher. One month after the launching of the study, the questionnaires were completed again by the subjects via WhatsApp social network. Data analysis was performed in SPSS version 16 using descriptive statistics (frequency distribution tables and numerical indices), followed by inferential statistics using Chi-square, Fisher's exact test, independent t-test, and paired t-test for the comparison of the study groups.

Results: No significant differences were observed between the intervention and control groups in terms of age, education level, place of residence, length of the neonate's admission, gender of the neonates, and mode of delivery between the intervention and control groups, and the groups were homogenous in this regard at the significance level of 0.05 . In addition, the results of independent $t$-test showed no significant difference between the intervention and control groups in terms of the score of chronic sorrow $(\mathrm{P}>0.05)$. After the intervention, the mean score of chronic sorrow in the control and intervention groups was $43.11 \pm 8.38$ and $32.85 \pm 5.45$, respectively, which indicated a significant difference in this regard $(\mathrm{P}<0.001)$. This finding indicated the effectiveness of the COPE program in decreasing the chronic sorrow of the parents of the premature infants admitted to the NICU.

Conclusion: According to the results, the symptoms of sorrow appeared in the parents in the intervention and control groups upon the admission of the premature neonates to the NICU. Therefore, the parents whose premature infants are admitted to the NICU require proper examination and treatment for the symptoms of sorrow. Our findings confirmed the effectiveness of the COPE program in the alleviation of the sorrow of the parents whose premature neonates were admitted to the NICU. Therefore, it is recommended that this program be implemented as an effective and cost-efficient strategy in NICUs. Furthermore, the use of audio-visual training programs along with routine treatments could positively influence the care of premature infants and reduce the psychological effects on care on the parents. Owing to technological advancement, the easy application of such educational programs could maintain the independence of families and increase the knowledge interaction of parents in the care of the newborn, while decreasing their stress and sorrow.

\section{Keywords: Chronic Sorrow, Empowerment, Premature Infants, Parents}

\section{Conflict of Interest: No}

How to Cite: Moradi H, Borimnejad L, Seyed Fatemi N, Haghani H, Mojgan Moradi M. The Effect of the Empowerment Program on the Chronic Sorrow of the Parents of Premature Newborn in Neonatal Intensive Care Units. Iran Journal of Nursing. 2019; 32(121):94-106.

Received: 23 Sep 2019

Accepted: 23 Dec 2019 


\title{
تأثير بر نامه توانمندسازى بر سوى مزمن والدين نوزاد نارس بسترى در بخش مر اقبت ويزه نوزادان
}

\author{
حميد مرادى'، ليلى بريم نزاد'، نعيمه سيدفاطمى"، حميد حقانى عُ، مزَّان مرادى
}

\section{جكبه}

زمينه و هدف: سوى يكى واكنش طبيعى به از دست دادن، تولد نوزاد نارس و يا غيرطبيعى است ولى در صورت طولانى شدن، خطر ابتلا به بيمارى

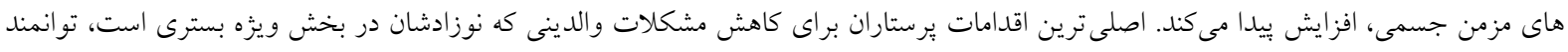

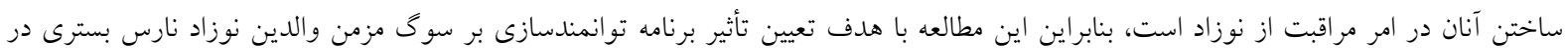
بخش مراقبت ويزٔه نوزادان انجام شد.

روش بررسى: اين مطالعه يك كارآزمايى بالينى غير تصادفى با كروه كنترل بود كه بر روى ل\ يدر و و مادر داراى نوزاد نارس بسترى در بخش مراقبت

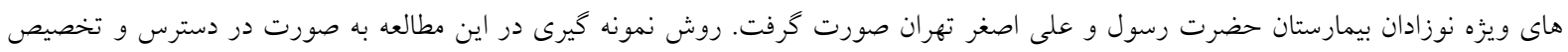

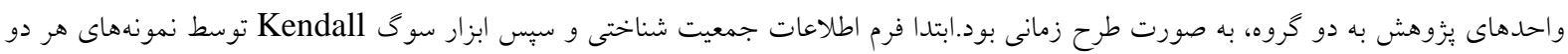

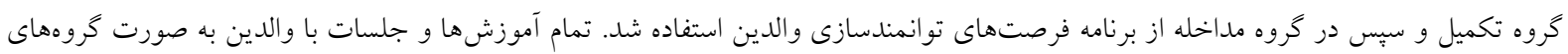

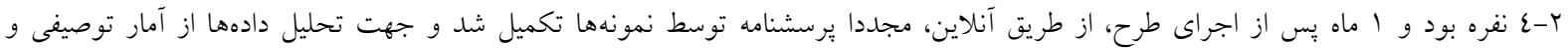

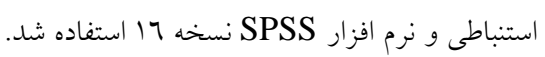

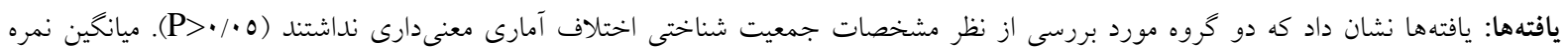

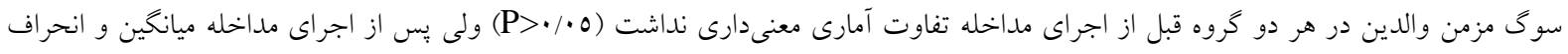

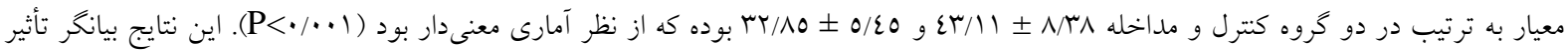

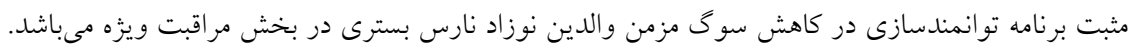

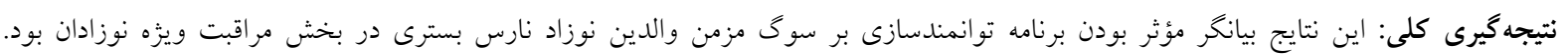
ييشنهاد مىشود اين برنامه به عنوان يك برنامه اثربخش و كم هزينه در بخش مر اقبت ويزه نوزادان مد نظر قرار گيرد.

كليدوازهها: سوى مزمن، برنامه توانمندسازى، والدين، نوزاد نارس

$$
\begin{aligned}
& \text { تعارض منافع: ندارد } \\
& \text { تاريخ دريافت: 9N/V/I } \\
& \text { تاريخ بذيرش: T/ • }
\end{aligned}
$$

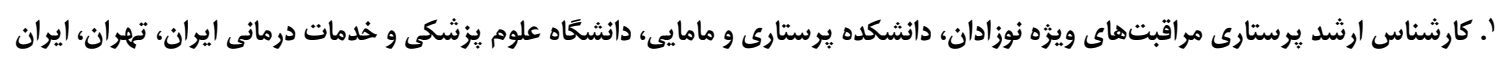

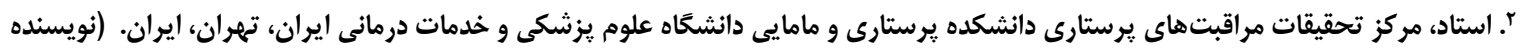
Email:borimnejad.l@iums.ac.ir 
نوزاد شامل: تولد زودرس، ناتوانى در رشد، سندرم داون،

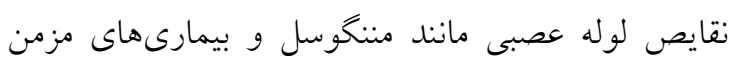

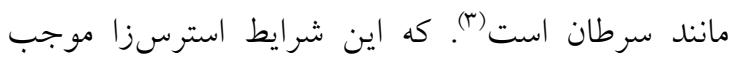

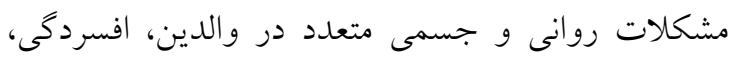

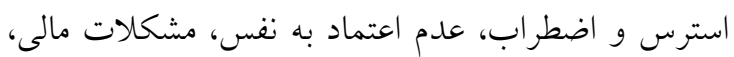

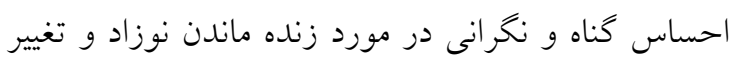
در نقش والدى شده و به خاطر شكل نغرفتن صحيح

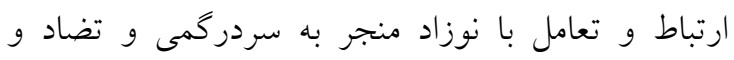

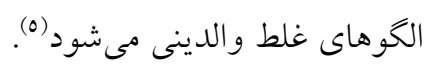
در واقع يك تجربه ناخوشايند براى بدر و مادئ مادر وقتى است كه فرزندشان زود متولد شده يا در بخش ويزه

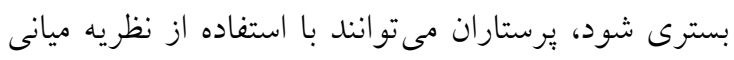

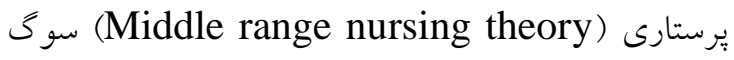
مزمن به ارزيابى خانواده براى بررسى علائم ترس،

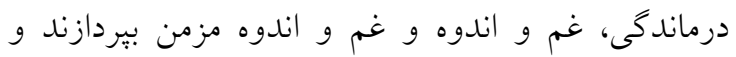

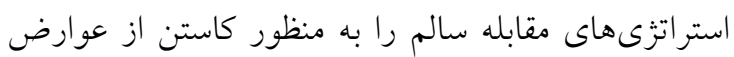

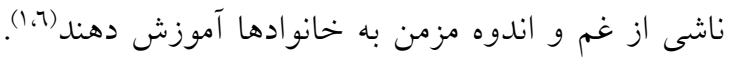

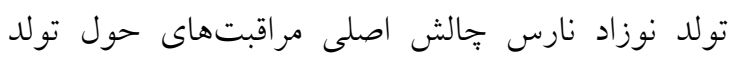

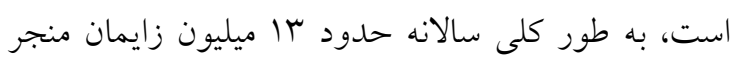

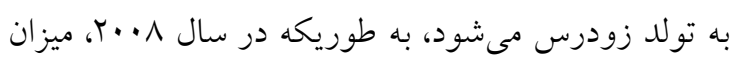

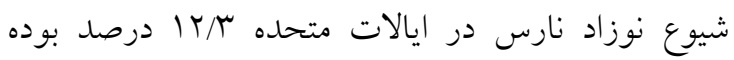

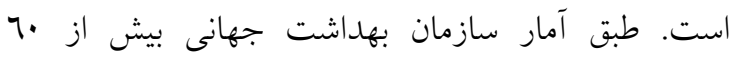

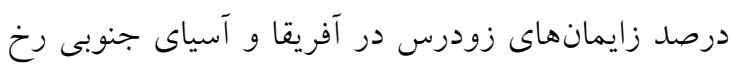

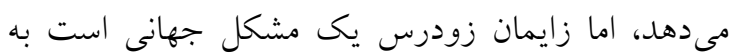

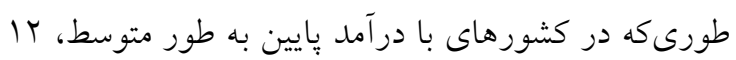

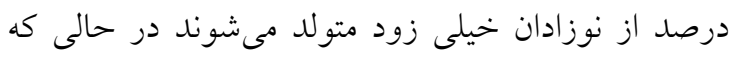

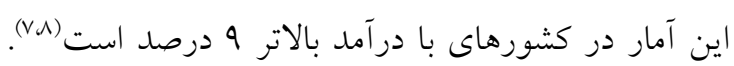

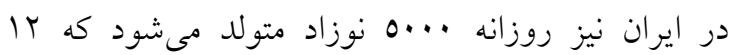

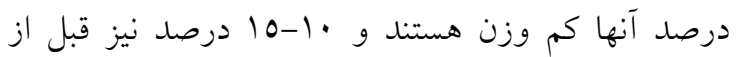
هفته MV باردارى متولد شده و نارس هستند. در يك

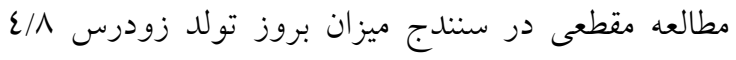
درصد و نوزاد كم وزن V/T درصد برآورد شده است. نتايج يزوهشى كه به بررسى وضيعت تولد در شهر شيراز

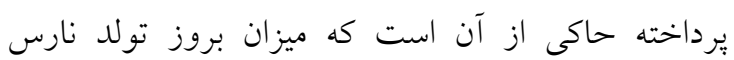

\section{مقدمه}

غم و اندوه مزمن به عنوان يكى واكنش عادى به رويدادى

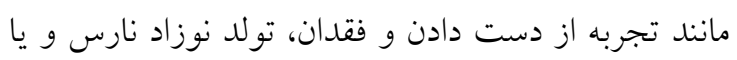
نوزاد غيرطبيعى است و جرخه آن به صورت نخرانى و نياز به كمك، دوره غم و اندوه طولانى، سطح بهبودى و دوره شادى است (1). سوى ياتولوزيك اختلال عمدهاى در كيفيت زندكى ايجاد مىكند و در فردى كه دجار اين نشانغان شده است، خطر ابتلا به بيمارىهاى مزمن جسمى، سوء مصرف مواد و خودكشى، افزايش بيدا مى كند و درجاتى از ناتوانى در عملكردهاى فردى و اجتماعى را براى وى به همراه دارد كه در نهايت مىتواند اثرات نامطلوبى بر روى ساختار خانواده و حتى جامعه داشته باشد (r).

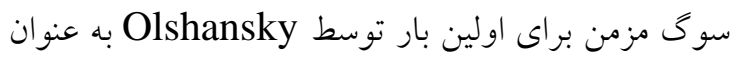

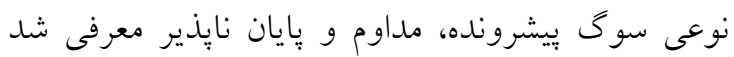

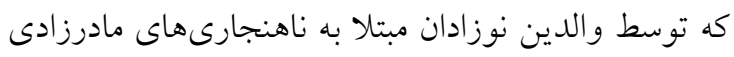

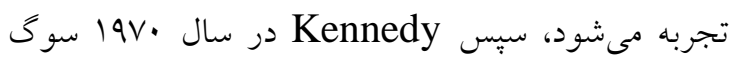
مزمن را غم و اندوهى كه بيش از r ب-r ماه طول بكشد، تعريف كرد عدهاى سوى را شامل دو بعد درونى (افكار و احساسات) و بيرونى (رفتارهاى مربوط به سوى مانند گريه كردن)

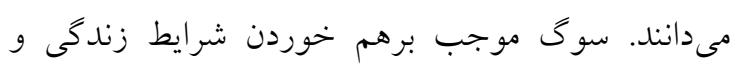

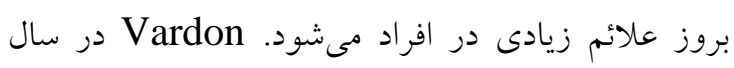

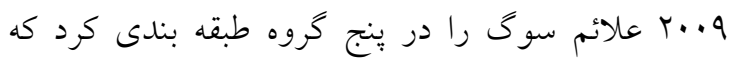

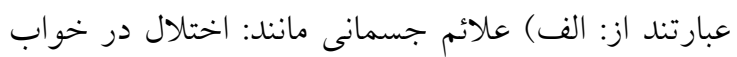
و خوراى، احساس فشار در كلو، سردرد، ب) علائم

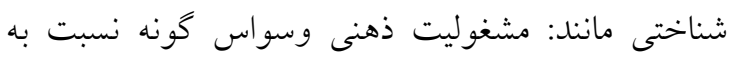
متوفى، بروز مشكلات حافظه و كاهش تمركز و انكار، ج)

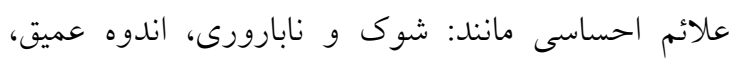

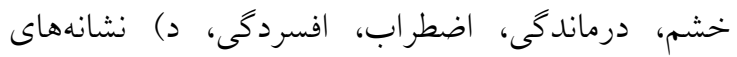
معنوى مانند: شك در اعتقادات و باورها و تلاش براى معنايابى، ه) علائم رفتارى مانند: كوشه گيرى، كريه كردن،

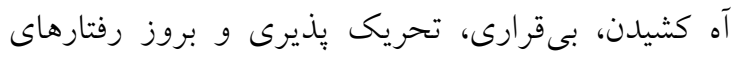

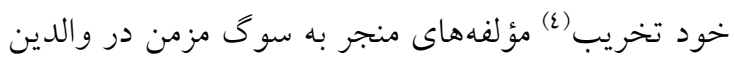




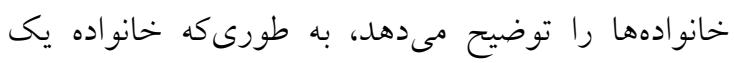
حس كنترل بر زندكىشان داشته باشند (rا،؛).

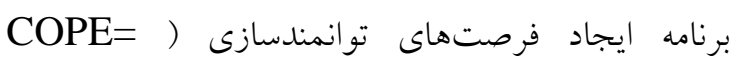

Creating opportunities for parent Melnyk كه در سال (empowerment براى والدين نوزاد نارس طراحى شده است، مداخلهاى

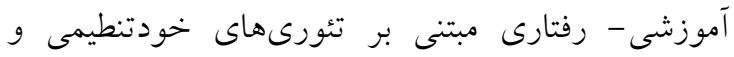

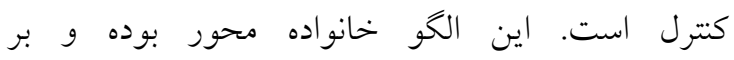

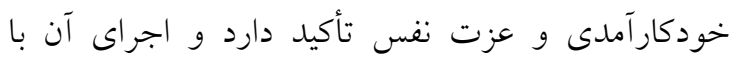

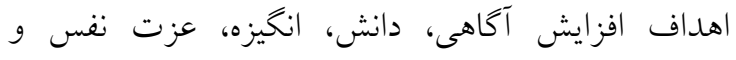

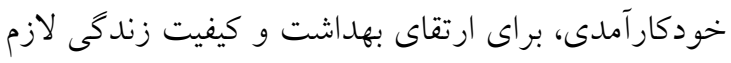
است. در اين برنامه علاوه بر حمايت روانى از والدين،

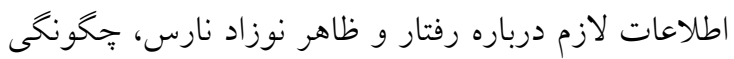
ايفاى نقش والدى و شرايط بخش ويزه و نحوه مراقبت از نوزاد نارس ارائه ميكردد (ع).

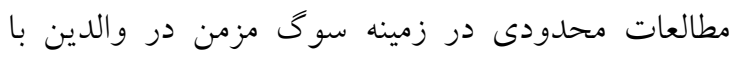

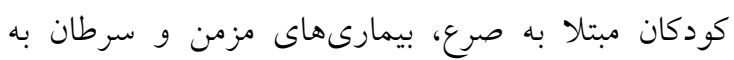

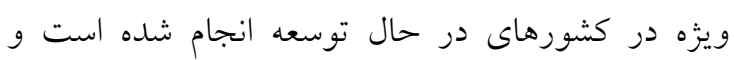

همجنين بر اساس نتايج مطالعه Sethaghlin and در سال Sethares بيشتر در زمينه اثربخشى مداخلات خانواده محور در

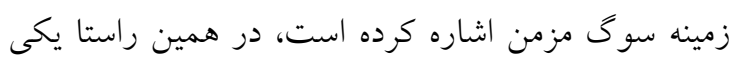

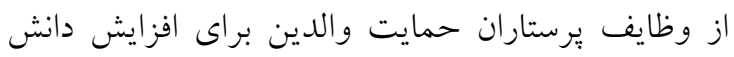

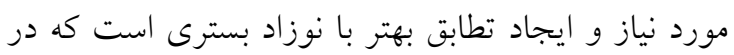

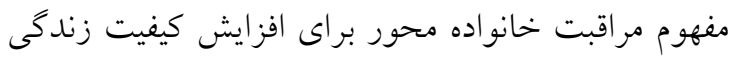

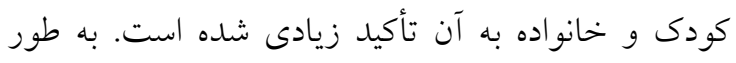

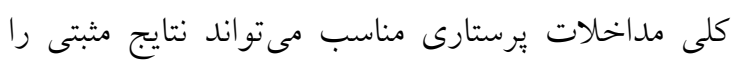
براى والدين به دنبال داشته باشد و از مسائلى مانند اندوه، استرس و تغيير نقش والدى بكاهد و از اصلىترين اقدامات برستاران براى كاهش مشكلات والدينى كه نوزادشان در بخش ويزه بسترى است، توانمند ساختن

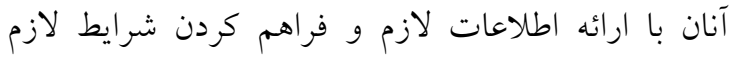

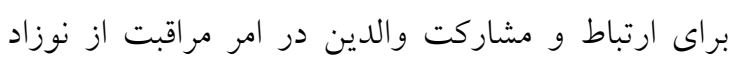

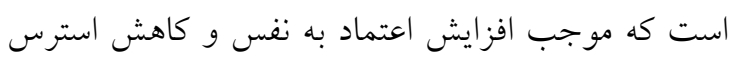

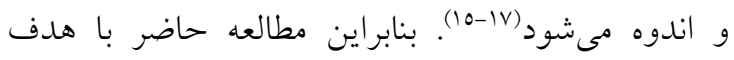

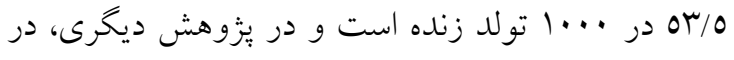

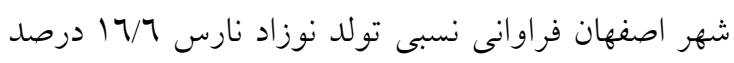

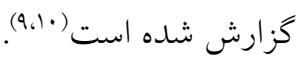
تولد نوزاد نارسى كه از بدو تولد نياز به بسترى در بخش

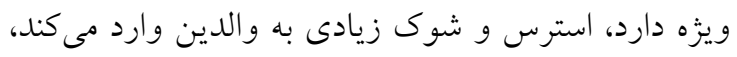
به طورى كه در مطالعه بهشتى ثيور و همكاران، ميانكين

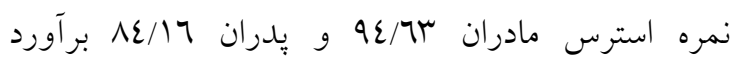
كرديده است(1'). در همين راستا يكى از وظايف يرستاران

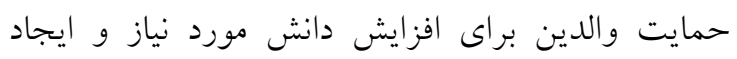

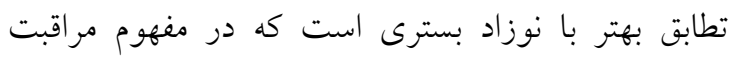

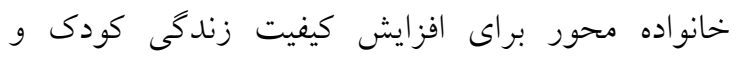

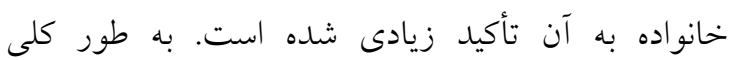
مداخلات برستارى مناسب مىتواند نتايج مثبتى را براى به رئ

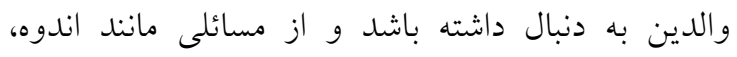
استرس و تغيير نقش والدى بكاهد و از اصلىترين

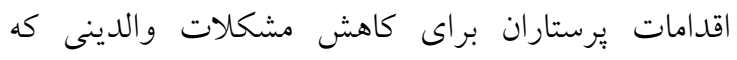
نوزادشان در بخش ويزه بسترى است، توانمندساختن آنان

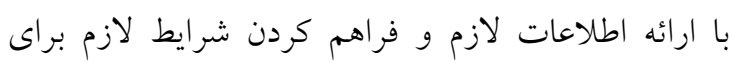

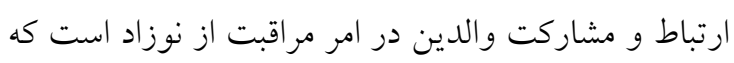
موجب افزايش اعتماد به نفس و كاهش استرس و و اندوه مىشود (0.1 (م).

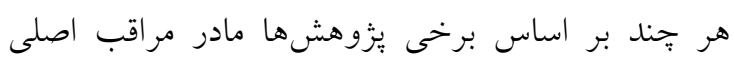

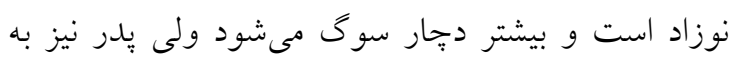

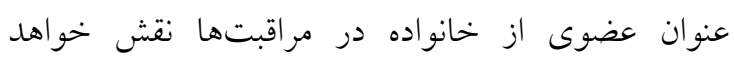

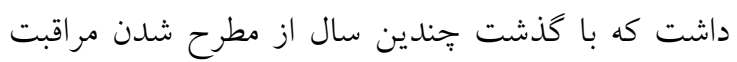

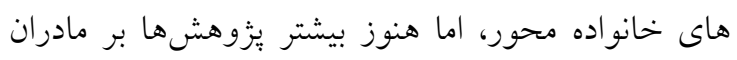
نوزاد بسترى در بخش ويزه متمركز بوده و اطلاعات

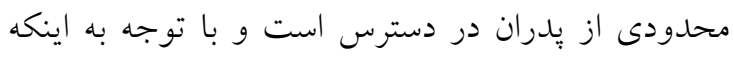

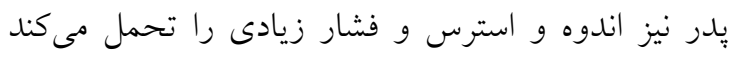

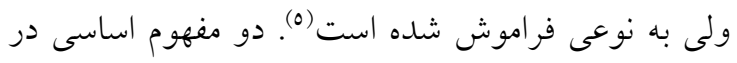

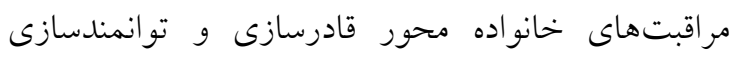

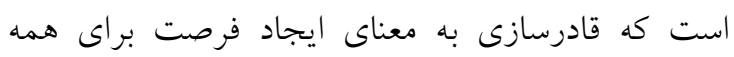

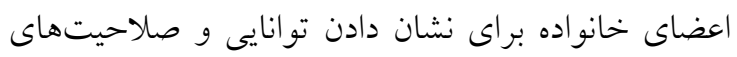
فعلىشان است و توانمندسازى تعاملات حرفهاى با باليان 


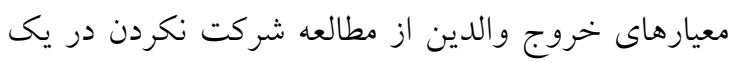

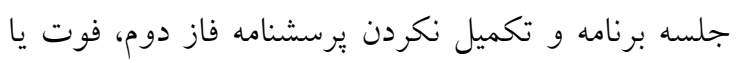

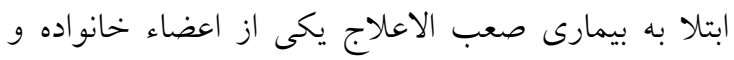

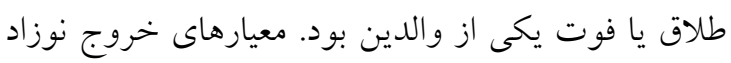

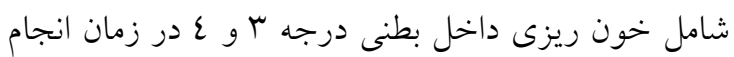

$$
\text { يُزوهش و فوت نوزاد بود. }
$$

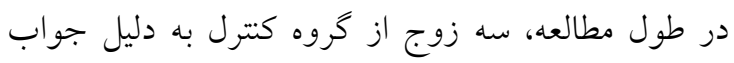

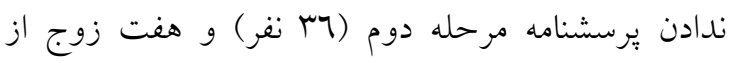

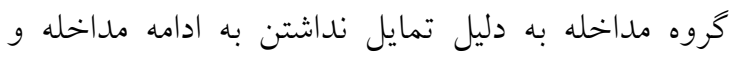

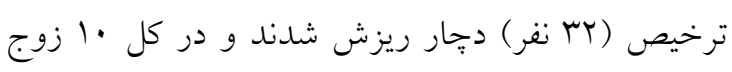
از مطالعه خارج شدند.

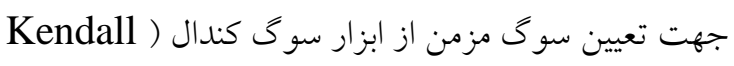
(Chronic Sorrow Questionnaire اين برسشنامه داراى \\ سئوال بوده و هدف آن ارزيابى سوگ مزمن از ابعاد مختلف (تناقض، اندوه، كنار آمدن)

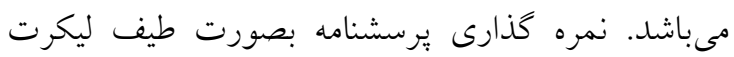

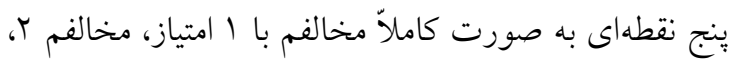

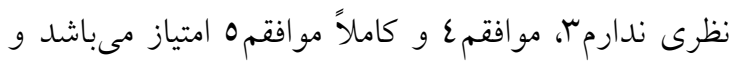

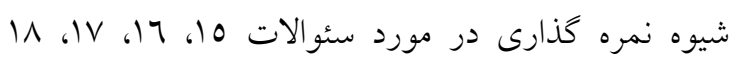

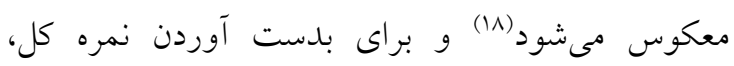

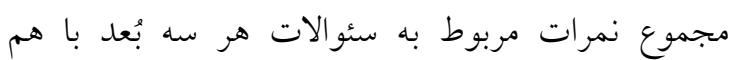

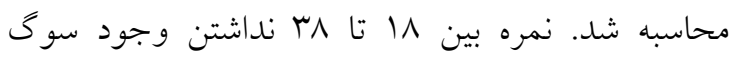

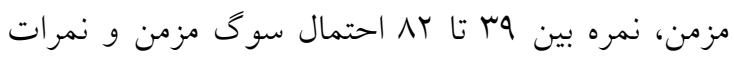

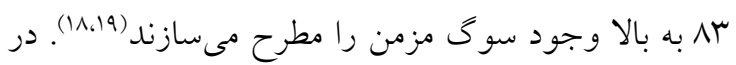
يزوهش نيك فريد و همكاران روايى سازه ابزار با استفاده از تحليل عاملى اكتشافى بررسى شد و آلفاى كرونباخ

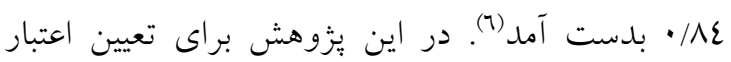

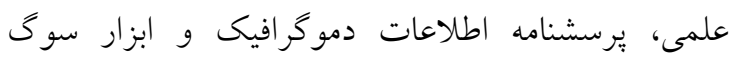
مزمن كندال از روش اعتبار صورى و محتوى استفاده شد

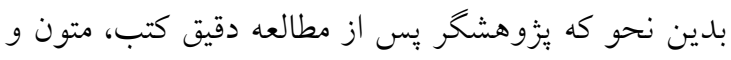

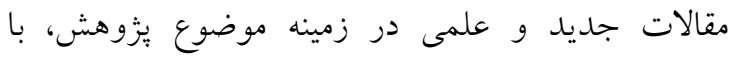

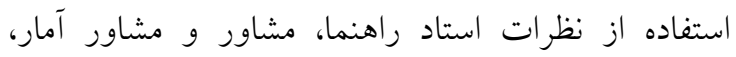
يرسشنامهها را تنظيم و در اختيار ينج نفر از اعضاى هيئت

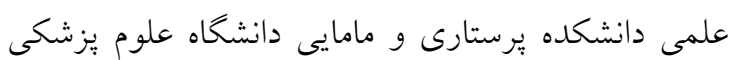

تعيين تأثير برنامه توانمندسازى بر سوگ مزمن والدين نوزاد بسترى در بخش ويزه نوزادان انجام شد.

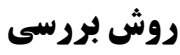
در اين مطالعه يك كار آزمايى بالينى غير تصادفى با گروه

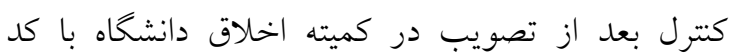

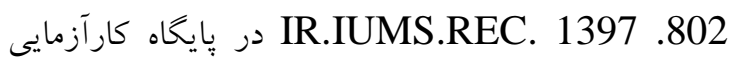
بالينى با كد IRCT20090405001788N22 شده است به بررسى تأثير برنامه توانمندسازى بر سوى بالئ

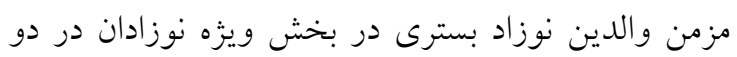

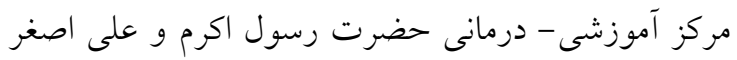
تهران يرداخته شده است. براى تعيين حجم نمونه لازم در إنى

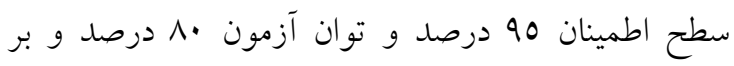

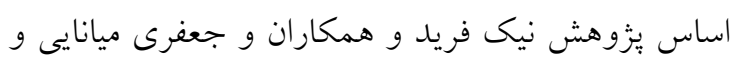

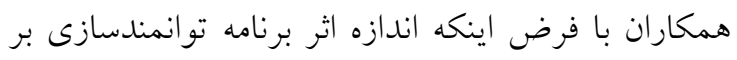
سوى مزمن والدين نوزاد نارس درمقايسه با گروه كنترل

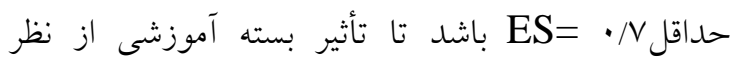

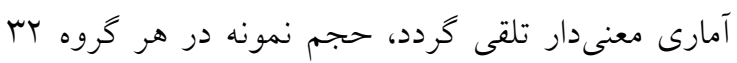

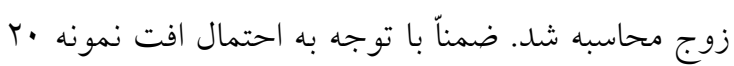
درصدى، در نهايت حجم نمونه در هر كروه و

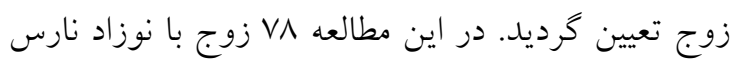

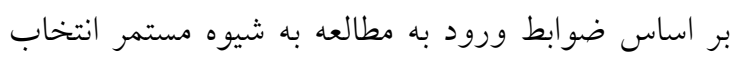

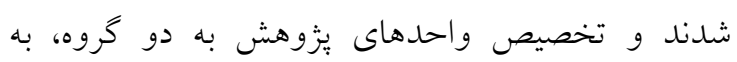
صورت طرح زمانى بود به طوريكه براى جلوكيرى از

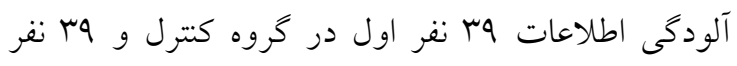

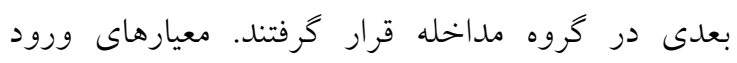

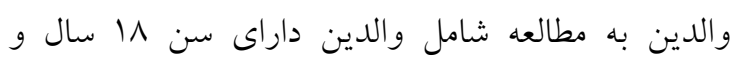

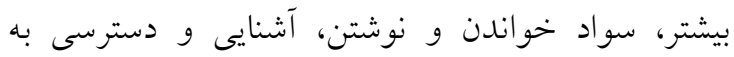

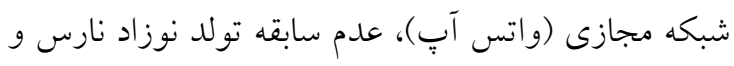

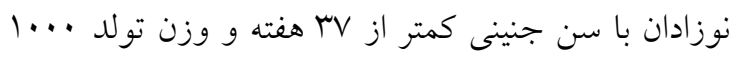
تا . . مr كرم بود. معيارهاى ورود نوزاد تكى قل بودن و بسترى بودن نوزاد حداقل به مدت يك هفته حين مداخله بود. 
نقش والدين در مراقبت از نوزاد نارس و يك كتابجه

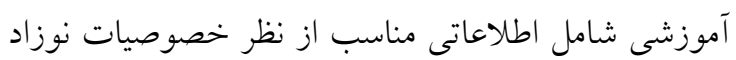

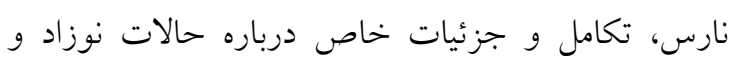
بهترين زمان براى تعامل و همجنين نقش والدين و نحوه

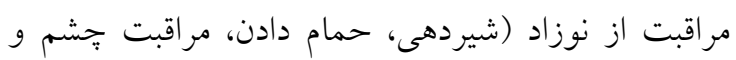

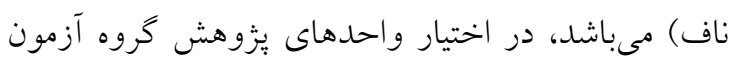

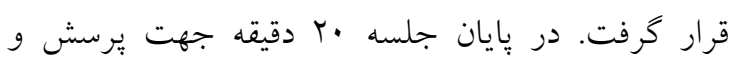
ياسخ در نظر كرفته شد. مرحله سوم: روز قبل از ترخيص از والدين در مورد مورد

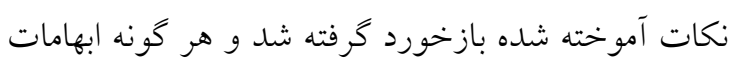

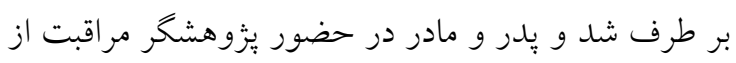
نوزادش را به صورت عملى انجام داد. همجنين شماره

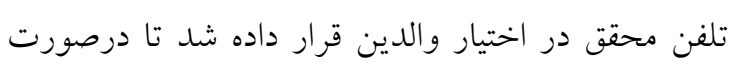

$$
\text { لزوم با او تماس بخيرند. }
$$

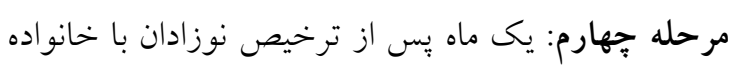

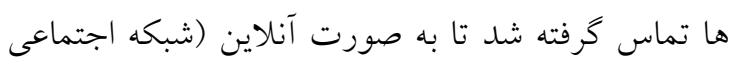
(Whats App در پايان مطالعه تمام مطالب آموزشى و فيلمها در اختيار كروه كترل نيز قرار كرفت.

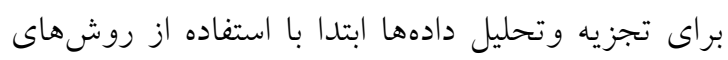

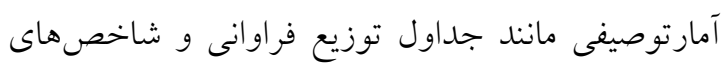

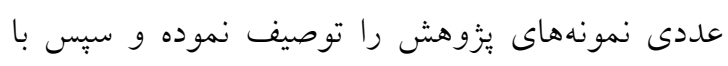

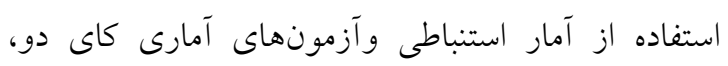

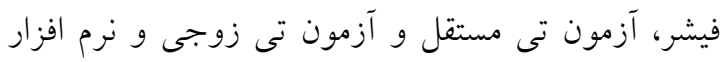
نسخه 17 در راستاى مقايسه دو گروه استفاده شد و سطح معنى دارى 0 × • در نظر كرفته شد.

يافتهها

اطلاعات بدست آمده در ارتباط با مشخصات جمعيت

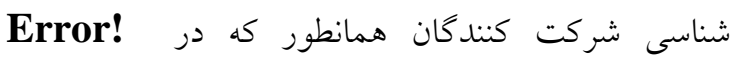

Error! , Reference source not found. Reference source not found. است، مشاركت كنندگان در دو گروه مداخله و كنترل از نظر متغيرهاى سن، سطح تحصيلات، محل زندگى، مدت مدات
ايران قرار داد و پِس از جمع آورى، نظرات اساتيد محترم

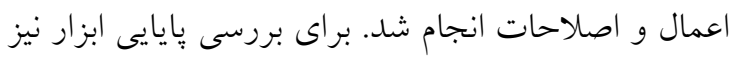

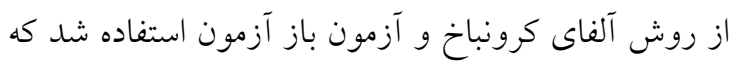
يرسشنامه توسط 10 زوج والد با فاصله يكى ماه تكميل

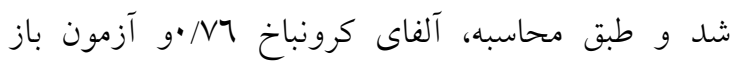

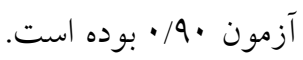
قبل از شروع به كار، ابتدا رضايت نامه آكاهانه جهت

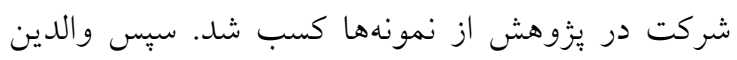

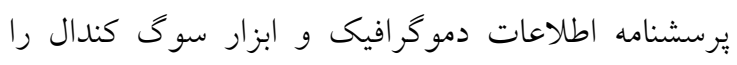

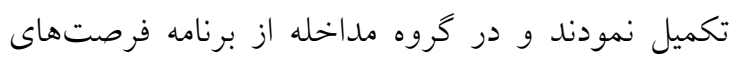

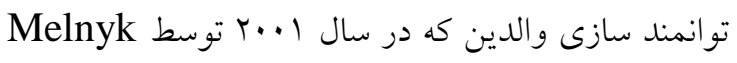
و همكاران براى والدين نوزاد نارس طراحى شده بون بود

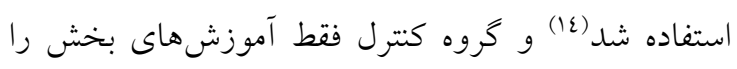

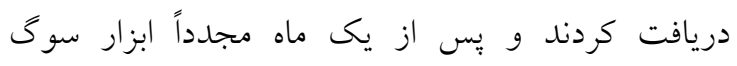

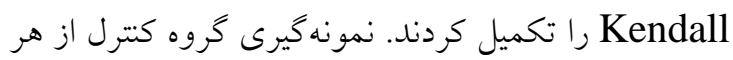

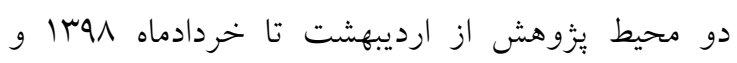

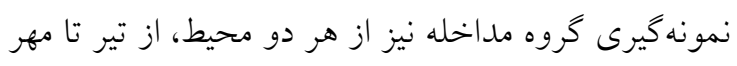

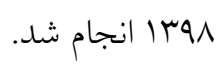
روند اجراى مداخله و برنامه آموزشى Melnyk

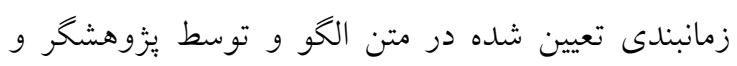
كمك يزوهشخر كه هر دو كارشناس ارشد يُرستارى بودند به ترتيب زير اجرا شد:

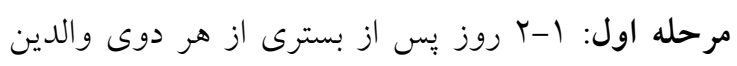

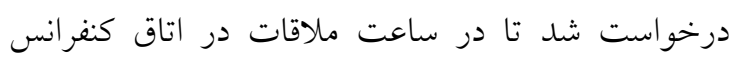

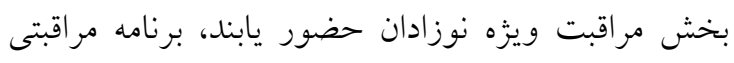

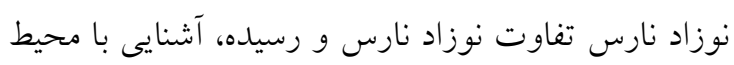

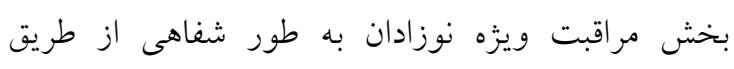

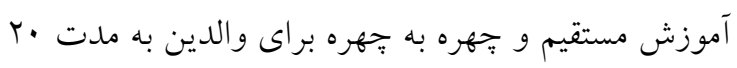
دقيقه بيان و نكات مراقبتى به صورت تئورى ارائه شد.

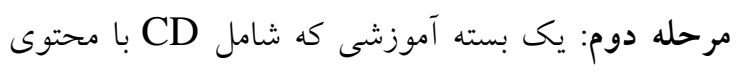

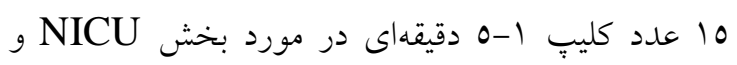

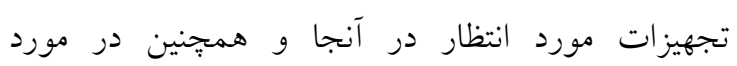

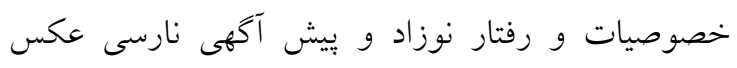

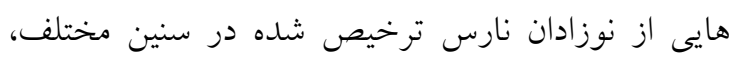




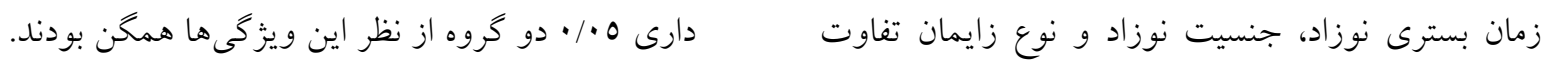

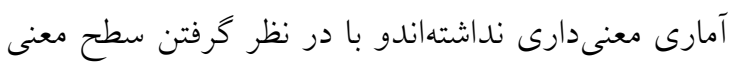

جدول شماره (: مشخصات دموتر افيك والدين واحدهاى مورد يزوهش (تعداد= ش زوج)

\begin{tabular}{|c|c|c|c|}
\hline نتايج آزمون & گروه كنترل (ךrn) تعداد (درصد) & كروه مداخله (Yr=r) تعداد (درصد) & متغييرها \\
\hline آزمون تى مستقل & & & سن يدران \\
\hline$t=\cdot / \varepsilon \cdot r \quad d f=77$ & (T) & $\left(\tilde{M} / \Gamma_{\cdot}\right) 1 \cdot$ & زير و ب \\
\hline \multicolumn{4}{|l|}{$\mathrm{P}=\cdot / \neg \Lambda$} \\
\hline & $(\varepsilon 1 / v \cdot) 10$ & $(\varepsilon r / \Lambda \cdot) \mid \varepsilon$ & rq-r. \\
\hline & $($ YO) 9 & $($ YO)^ & بالاى ·ع سال \\
\hline & $V / \Lambda r \pm r r / \varepsilon \varepsilon$ & $V / \mu l \pm r \varepsilon / \Lambda \Lambda$ & انحراف معيار 土 ميانخين \\
\hline آزمون تى مستقل & & & سن مادران \\
\hline $\mathrm{t}=\cdot \mu \mathrm{r} r \quad \mathrm{df}=77$ & $(\varepsilon V / Y) \mid V$ & $(\Sigma 7 / 9) 10$ & زير و T \\
\hline \multicolumn{4}{|l|}{$\mathrm{P}=\cdot / \mathrm{NI}$} \\
\hline & $(\Sigma V / T) \mid V$ & $(\mathrm{Or} / \mathrm{I}) \mathrm{IV}$ & rq-r. \\
\hline & $(0 / 7) r$ & $(\cdot) \cdot$ & بالاى ·ع سال \\
\hline & $0 / 9 V \pm r \Lambda / \Sigma V$ & $\eta / r\urcorner \pm r q / \cdot r$ & انحراف معيار 土 ميانخين \\
\hline آزمون دقيق فيشر & & & تحصيلات بدران \\
\hline \multirow[t]{4}{*}{$\mathrm{P}=\cdot / \Lambda \Lambda V$} & $(T / \Lambda) 1$ & $(\cdot) \cdot$ & بيسواد \\
\hline & $(11 / 1) \varepsilon$ & $(10 / 7) 0$ & زير دييلم \\
\hline & $(0 T / 1) 19$ & $(\Sigma 7 / 9) 10$ & دييلم \\
\hline & $(r \mu / \mu) \mid r$ & $(r V / 0) \mid r$ & 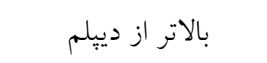 \\
\hline آزمون دقيق فيشر & & & تحصيلات مادران \\
\hline \multirow[t]{4}{*}{$\mathrm{P}=\cdot / V T r$} & $(T / \Lambda) 1$ & $(\cdot) \cdot$ & بيسو اد \\
\hline & $(1 \mathrm{~T} / \mathrm{V}) \mathrm{T}$ & $(9 / \varepsilon) r$ & زير دييلم \\
\hline & $(\Sigma V / T) \mid V$ & $(07 / \Gamma) \backslash \Lambda$ & دييلم \\
\hline & $(\Gamma / \mu) \mid r$ & $(r \varepsilon / \varepsilon) 11$ & بالاتر از دييلم \\
\hline آزمون دقيق فيشر & & & محل زندگى \\
\hline \multirow[t]{3}{*}{$\mathrm{P}=\cdot N M^{\mu}$} & $(O \Lambda / \varepsilon) r I$ & $(0 \mathrm{O} / \mathrm{I}) \mathrm{IV}$ & تهران \\
\hline & (T/T) IT & $(\Gamma \mid \Gamma) 1$. & حومه تهران \\
\hline & $(\Lambda / \Gamma) r$ & $(10 / 7) 0$ & غيره \\
\hline
\end{tabular}


جدول شماره ז: مشخصات دمو

\begin{tabular}{|c|c|c|c|}
\hline نتايج آزمون & گروه كنترل (7r=r) تعداد (درصد) & گروه مداخله (Yr=r) تعداد (درصد) & متغير ها \\
\hline آزمون كاى دو & & & مدت زمان بسترى نوزاد \\
\hline \multirow{5}{*}{$\begin{array}{c}\mathrm{X}^{2}=r \quad \mathrm{df}=r \\
\mathrm{P}=\bullet / \wedge r\end{array}$} & $(\mu / \mu \cdot) \mid r$ & $\left(\sum 7 / 9\right) 10$ & 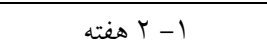 \\
\hline & & & \\
\hline & $($ YO) 9 & $(\Gamma, / Y) 1$. & Y Y T هفته \\
\hline & $\left(T_{0}\right) 9$ & $(r / 1) 1$ & r-ץ هفته \\
\hline & $(1 \mathrm{~T} / \mathrm{V}) \mathrm{T}$ & $(\mid \Lambda / \Lambda)\rceil$ & بيش از ع هفته \\
\hline آزمون كاى دو & & & جنسيت نوزاد \\
\hline $\mathrm{X}^{2}=\cdot \mu r V \quad \mathrm{df}=1$ & $(\varepsilon \varepsilon / \varepsilon) 17$ & $(r V / 0) \backslash r$ & دختر \\
\hline \multicolumn{4}{|l|}{$\mathrm{P}=\cdot \mu v$} \\
\hline & $(00 / 7) r \cdot$ & $(7 r / 0) r \cdot$ & يسر \\
\hline آزمون كاى دو & & & نوع زايمان \\
\hline $\mathrm{X}^{2}=\cdot / \cdot 1 \quad \mathrm{df}=1$ & $(Y Y / Y) \wedge$ & $(Y \backslash / 9) V$ & طبيعى \\
\hline \multicolumn{4}{|l|}{$\mathrm{P}=\cdot / 7 \cdot \mu$} \\
\hline & $(V V / \Lambda) Y \Lambda$ & $(V N / I)$ ro & سزارين \\
\hline
\end{tabular}

ع 9 درصد از والدين گروه كنترل سوگ مزمن داشتند اما

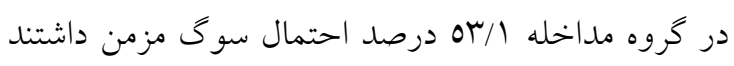

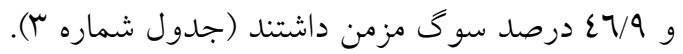

بر اساس نمره كسب شده، قبل از مداخله ع/ع9 درصد والدين گروه كنترل و 1/ بر درصد و الدين كروه مداخله در گروه سوگ مزمن قرارداشتند. يّ از اجراى مداخله

جدول شماره ساتوزيع فراوانى سوتى مزمن والدين در واحدهاى مورد يزوهش قبل و بعد از مداخله

\begin{tabular}{|c|c|c|c|c|c|c|c|c|}
\hline \multicolumn{4}{|c|}{ بعد } & \multicolumn{4}{|c|}{ قبل } & \multirow[t]{3}{*}{ گروه } \\
\hline \multicolumn{2}{|c|}{ 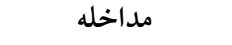 } & \multicolumn{2}{|c|}{ 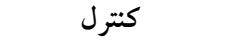 } & \multicolumn{2}{|c|}{ 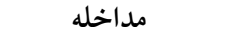 } & \multicolumn{2}{|c|}{ 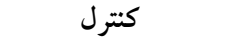 } & \\
\hline درصد & 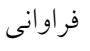 & درصد & 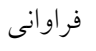 & ل مرصد & 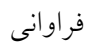 & ل مرصد & 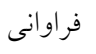 & \\
\hline $0 r / 1$ & IV & $0 / 7$ & r & $1 / 1 /$ & 7 & $0 / 7$ & r & 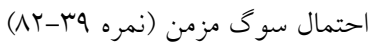 \\
\hline$\varepsilon 7 / 9$ & 10 & $9 \varepsilon / \varepsilon$ & $r \varepsilon$ & $\Lambda 1 / r$ & r & $9 \varepsilon / \varepsilon$ & $r \varepsilon$ & 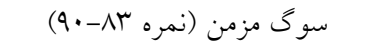 \\
\hline $1 \cdots$ & rt & $1 \cdots$ & m & $1 \cdots$ & rr & $1 \cdots$ & m & جمع \\
\hline
\end{tabular}

سوگ مزمن قبل و بعد از مداخله در گروه مداخله به ميزان

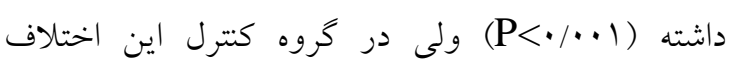

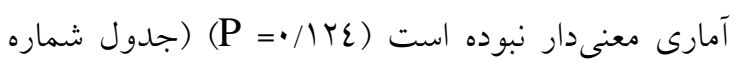
. $(\varepsilon$
نتايج آزمون تى مستقل نشان داد دو گروه مورد يزوهش قبل از مداخله از نظر ميانخين نمره سوگ، اختلاف آمارى معنى دارى نداشتند (T/Y.T مداخله، ميانخين نمره كسب شده در گروه مداخله به طور معنى آزمون تى زوجى نشان دهنده آن بود كه ميانكين نمره 
جدول شماره ع: شاخصهاى عددى سوكى مزمن والدين در واحدهاى مورد يزوهش قبل و بعد از مداخله و آزمون معنىدارى

\begin{tabular}{|c|c|c|c|}
\hline \multirow[t]{2}{*}{ نتيجه آزمون تى مستقل } & مداخله & كنترل & \multirow[t]{2}{*}{ سوى مزمن } \\
\hline & انحر اف معيار 土 ميانخين & انحر اف معيار 土 ميانخين & \\
\hline $\mathrm{t}=\cdot / 0 \mathrm{rr} \quad \mathrm{df}=77 \quad \mathrm{P}=\cdot / 7 \cdot r$ & $20 / 0 V \pm 11 / r 7$ & $\left.\sum\right\rceil / \Lambda \Lambda \pm 9 / \mu \Lambda$ & قبل \\
\hline \multirow[t]{2}{*}{$t=0 / 19 \quad \mathrm{df}=77$} & $r / 1 / 0 \pm 0 / 20$ & $\varepsilon \Re /\rceil \pm \wedge / \uparrow \wedge$ & بعد \\
\hline & $\mathrm{t}=0 / 07 \quad \mathrm{df}=r_{1} \quad \mathrm{P}<\cdot / \cdots 1$ & $\mathrm{df}=r_{0} \quad \mathrm{P}=\cdot / r \varepsilon$ & نتيجه آزمون تى زوجى \\
\hline
\end{tabular}

ترس مادر به دليل كمبود آكاهى از ويزگى هاى رفتارى و

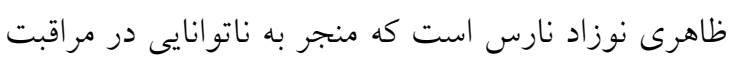
از نوزاد شده است.

Aho نوزادشان در بخش مراقبتهاى ويزه فوت شده را تأييد مى كند و اين غم و اندوه را مستلزم حمايتهاى روانى توسط برسنل مى داند Roose و همكاران در ايالات

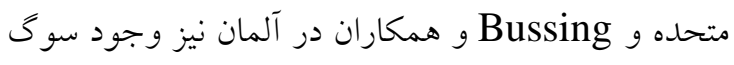

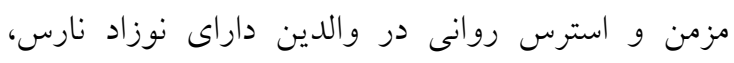

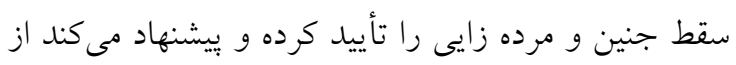

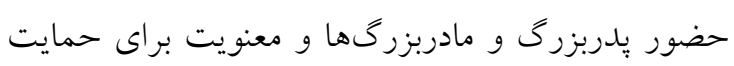

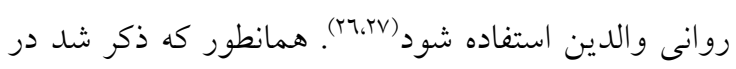

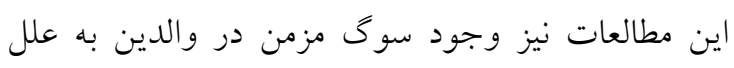
مختلف مانند بسترى و مرى نوزاد رخخ مى دهد كه مستلزم

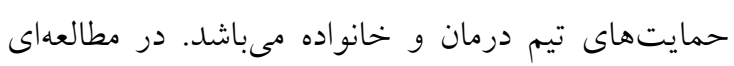

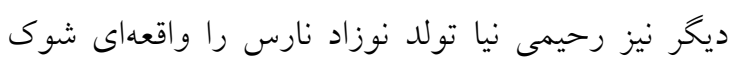

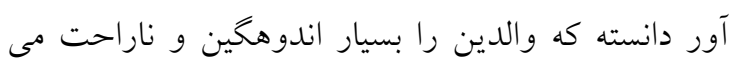
كند به طورى كه براى تسكين غم خود به حمايتهاي ولنه

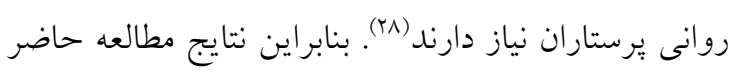
همر استا با مطالعات ذكر شده است.

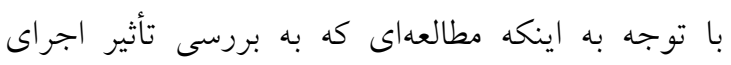

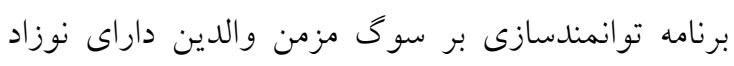

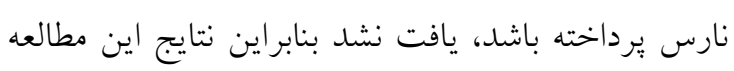

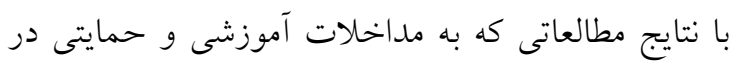
جهت كاهش مشكلات روانى و استرس والدين برداخته

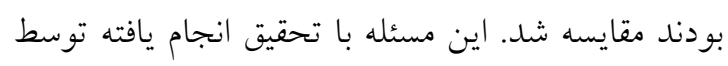

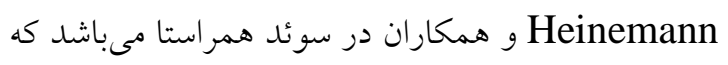

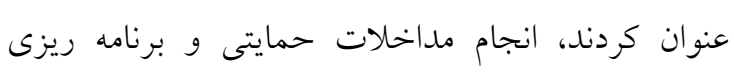

\section{بحث و نتيجه تيرى}

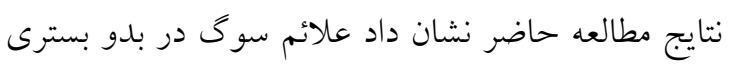

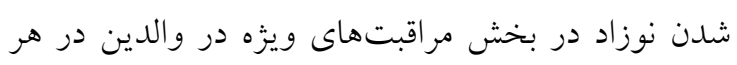

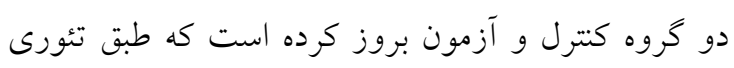

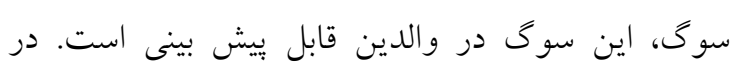

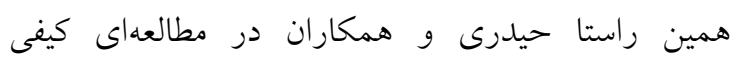

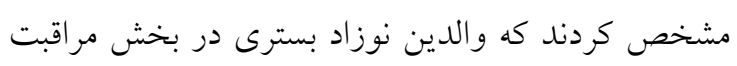

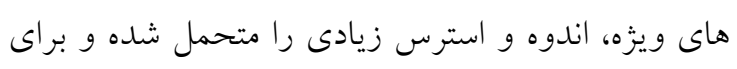

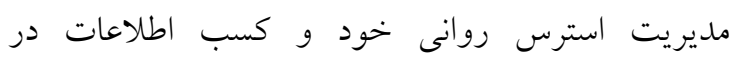
جستجوى برقرارى ارتباط هرجه بيشتر با تيم درمان

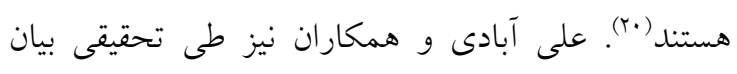

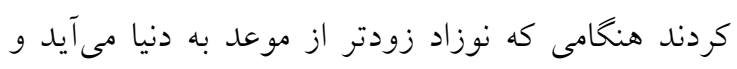

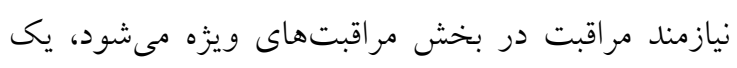

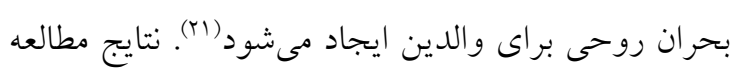

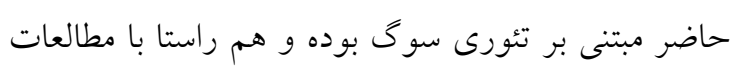
ديخر است.

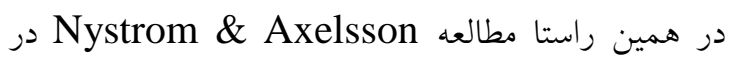

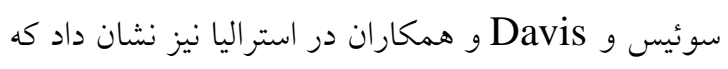

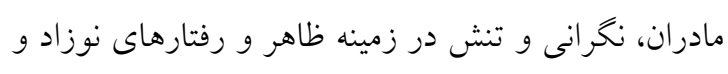

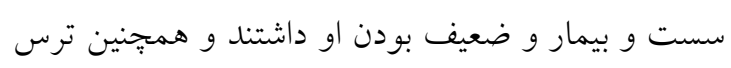

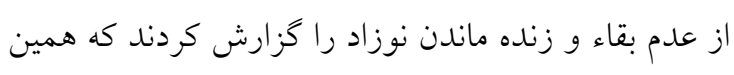
موارد موجب اندوه ناشى از جدايى و غم فقدان در آنها مىشود كه در مواقع بحرانى، توانيى مراقبت از فرزندشان اندان

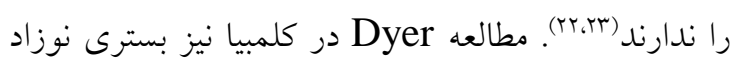

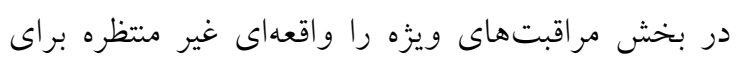

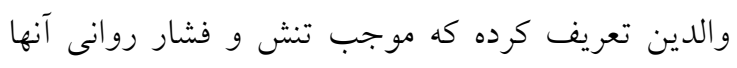

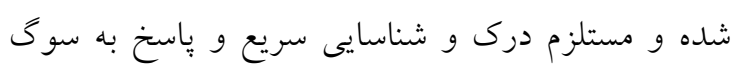

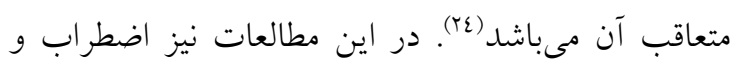


مطالعه بهشتى يور و همكاران كه به مقايسه سطح استرس ن.

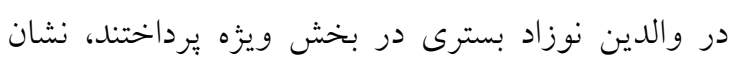

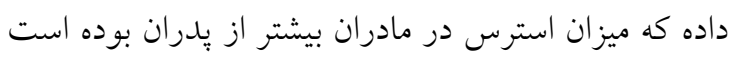

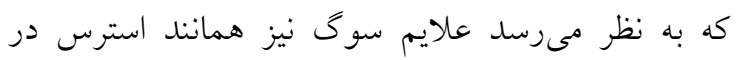

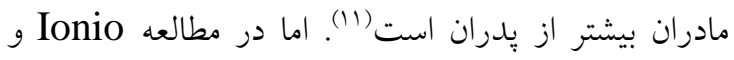

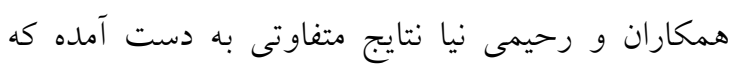

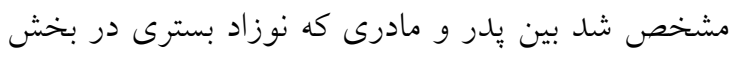

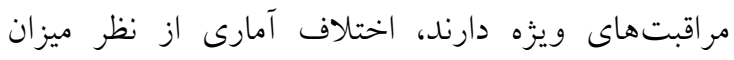
استرس وجود ندارد كه با نتايج مطالعات ذكر شده در درس

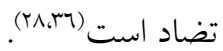
يافتهاى اين يُزوهش مىتواند به دليل توجه و كاربرد

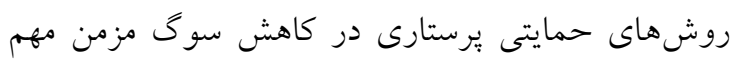

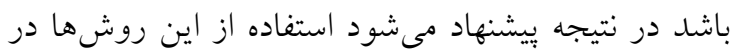
بالين مورد توجه قرار گيرد كه نيازمند آموزش يرستاران و

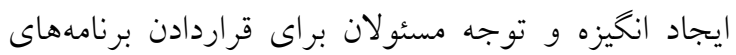

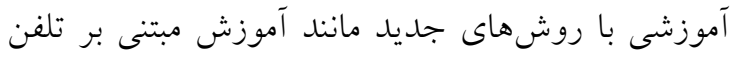

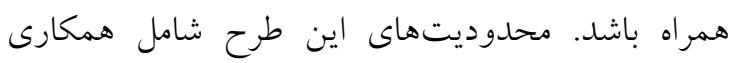

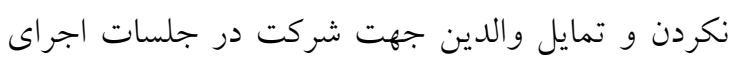

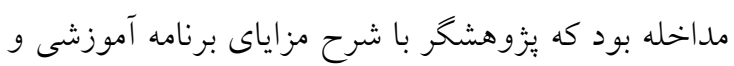

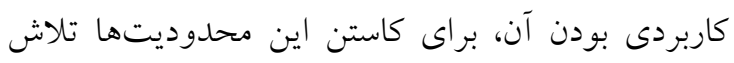
نمود.

تعارض منافع: هيج كونه تعارض منافع از سوى نويسند كان كزارش نشده است.

\section{تقدير و تشكر}

لازم است از همكارى كاركنان بخش مراقبت اقتهاى ويزه

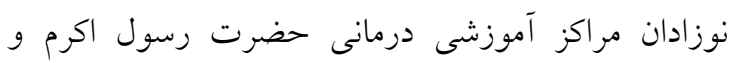
على اصغر و تمامى والدينى كه در اين طرح شركت درنس

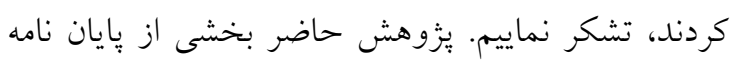

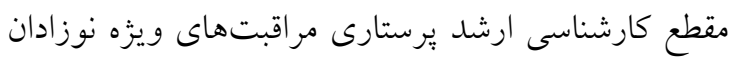
دانشخاه علوم يزشكى ايران است.
آموزشى جهت كم كردن استرس والدين در بخش مر اقبت

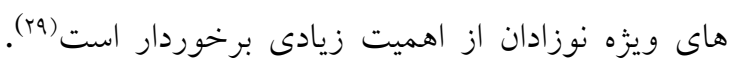

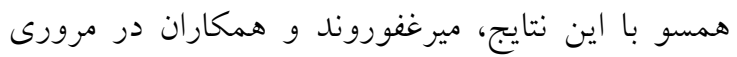

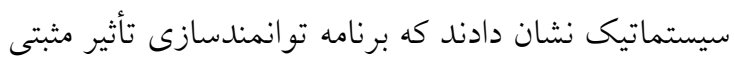

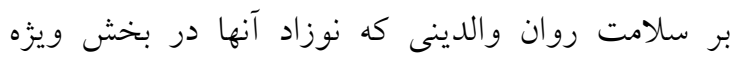

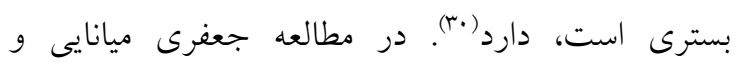
همكاران نيز بيان شده كه برنامه توانمندسازى والدين بارئ

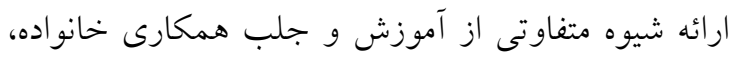

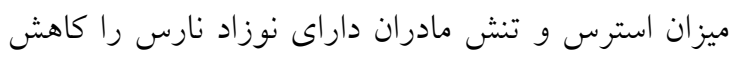
و ميزان مشاركت آنها را افزايش مى دهد (1). در همين راستا در مطالعه Coughlin و همكاران نيز كه دهن

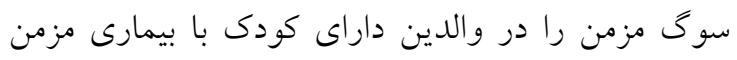
بررسى كرده است، يافتهها حاكى از آن است كه مادران

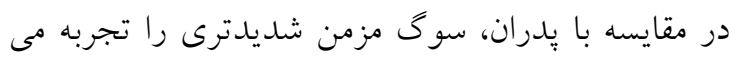

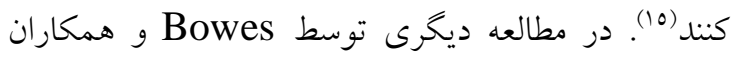
در انخليس كه ميزان سوى مزمن در والدين با فرزندان

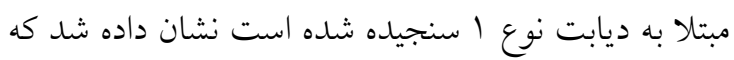

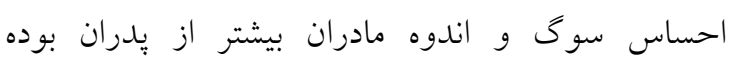

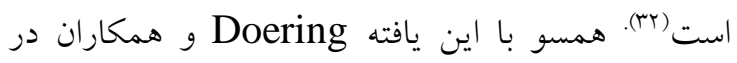
كاليفرنيا نيز در مطالعه خود به ساز كارى كمتر، نخر انى و

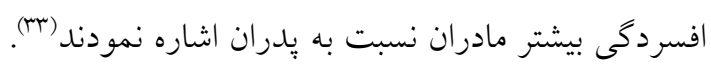

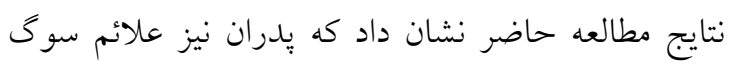

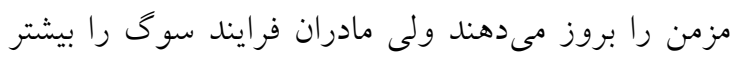

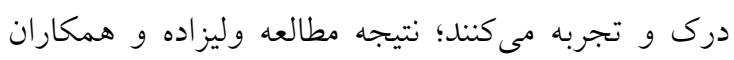
كه به مقايسه واكنش سوى مقدماتى در مادران و يدران نوزادان نارس بسترى در بخش مراقبت ويزه نوزادادان

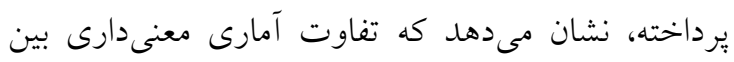

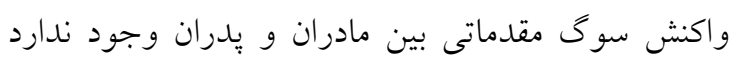

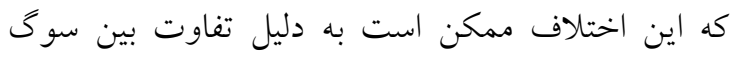

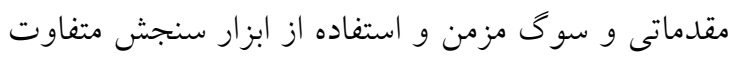

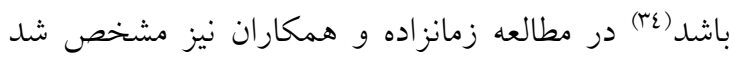
كه سوگ مزمن علاوه بر مادران در بِدرانى كه نوزادشان

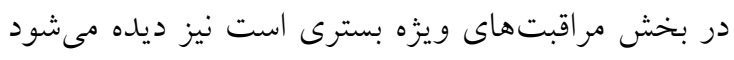

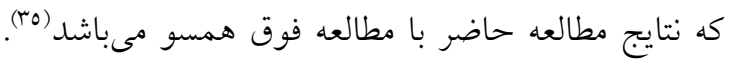




\section{References}

1. Vitale SA, Falco C. Children born prematurely: risk of parental chronic sorrow. J Pediat Nurs. 2014;29(3):248-51.

2. Nematipour z, Golzari mahmoud, Baqeri fariborz. evaluating the effectiveness of collective patience training on reduction of depression and stress symptoms of bereaved mother. Journal of Clinical Psychology Studies. 2012;2(7):31-59. [Persian]

3. Hobdell E. Chronic sorrow and depression in parents of children with neural tube defects. $J$ Neurosci Nurs. 2004;36(2):82.

4. Ghamari Givi H, Zahed A, Fathi D. Effectiveness of group cognitive-behavioral therapy on depression among the mournful elderly. Journal of Geriatric Nursing. 2016;2(3):22-31.

5. Khajeh M, Sadat Hosseini AS, Karimi R. The effect of parents empowerment program on their beliefs about parental role, behaviors and characteristics of their premature infants in nicu. The Journal of Urmia Nursing and Midwifery Faculty. 2013;11(6):419-27. [Persian]

6. Nikfarid L, Rasuli M, Borimneghad L, Alavimajd H. Psychometric Characteristics of Persian Version of Kendall Chronic Sorrow Instrument (KCSI) in Mothers of Children with Cancer. Iranian Journal of Psychiatry \& Clinical Psychology. 2014;20(2):144-52. [Persian]

7. Mathews TJ, Miniño AM, Osterman MJ, Strobino DM, Guyer B. Annual summary of vital statistics: 2008. Pediatrics. 2011;127(1):146-57.

8. W.H.O. preterm-birth 2018 [cited 2019/9/12 2019/9/12]. Available from: https://www.who.int/news-room/fact-sheets/detail/preterm-birth.

9. Kalhor ME, SamieeRad F, Garshasbi MA, MohitAbadi ZA, Sefollah SI. Evaluating the effect of mother-baby skin-to-skin care on neonatal outcomes in preterm infants. SSU_Journals. 2016;24(5):375-86. [Persian]

10. Khanjari S, Mosavipoor SS, Oskouie F, Haghani H. Quality of life and sense of coherence in the mothers with term and preterm infants. Iran Journal of Nursing. 2017;30(106):57-67. [Persian]

11. Beheshtipour N, Baharlu SM, Montaseri S, Razavinezhad AS. Comparison of parental stress in premature infants admitted in neonatal intensive care unit (NICU). Sadra Medical Sciences Journal. 2014;2(4):361-68. [Persian]

12. Nikfarid L, Eezadi H, Shakoori M. Coping Behaviors of Mothers of Chronically Ill Children. Iran Journal of Nursing. 2012;24(74):53-62. [Persian]

13. Masoodi R, Alhani F, Rabiei L, Majdinasab N, Moghaddasi J, Esmaeili SA, Noorian C. The effect of family-centered empowerment model on quality of life and self efficacy of multiple sclerosis patients family care givers. Iranian Journal of Nursing Research. 2013;7(27):32-43. [Persian]

14. Melnyk BM, Feinstein NF, Alpert-Gillis L, Fairbanks E, Crean HF, Sinkin RA, Stone PW, Small $\mathrm{L}$, Tu X, Gross SJ. Reducing premature infants' length of stay and improving parents' mental health outcomes with the Creating Opportunities for Parent Empowerment (COPE) neonatal intensive care unit program: a randomized, controlled trial. Pediatrics. 2006;118(5):e1414-27.

15. Coughlin MB, Sethares KA. Chronic sorrow in parents of children with a chronic illness or disability: An integrative literature review. J Pediat Nurs. 2017;37:108-16.

16. Hobdell EF, Grant ML, Valencia I, Mare J, Kothare SV, Legido A, Khurana DS. Chronic sorrow and coping in families of children with epilepsy. J Neurosci Nurs. 2007;39(2):76-82.

17. Nikfarid L, Rassouli M, Borimnejad L, Alavimajd H. Chronic sorrow in mothers of children with cancer. Journal of Pediatric Oncology Nursing. 2015;32(5):314-9. [Persian]

18. Kendall LC. The experience of living with ongoing loss: Testing the Kendall Chronic Sorrow Instrument. Virginia Commonwealth University; 2005.

19. Masterson MK. Chronic sorrow in mothers of adult children with cerebral palsy: An exploratory study (Doctoral dissertation, Kansas State University).

20. Heidari H, Hasanpour M, Fooladi M. Stress Management among Parents of Neonates Hospitalized in NICU: A Qualitative Study. J Caring Sci. 2017;6(1):29-38. [Persian]

21. Aliabadi F, Kamali M, Borimnejad L, Rassafiani M, Rasti M, Shafaroodi N, Rafii F, Kachoosangy RA. Supporting-emotional needs of Iranian parents with premature infants 
admitted to Neonatal Intensive Care Units. Medical journal of the Islamic Republic of Iran. 2014;28:53. [Persian]

22. Davis L, Edwards H, Mohay H, Wollin J. The impact of very premature birth on the psychological health of mothers. Early human development. 2003;73(1-2):61-70.

23. Nyström K, Axelsson K. Mothers' experience of being separated from their newborns. Journal of Obstetric, Gynecologic, \& Neonatal Nursing. 2002;31(3):275-82.

24. Dyer K. Identifying, understanding, and working with grieving parents in the NICU, part I: Identifying and understanding loss and the grief response. Neonatal Network. 2005;24(3):35-46.

25. Aho AL, Åstedt-Kurki P, Tarkka MT, Kaunonen M. Development and implementation of a bereavement follow-up intervention for grieving fathers: an action research. J Clin Nurs. 2011;20(3-4):408-19.

26. Roose RE, Blanford CR. Perinatal grief and support spans the generations: parents' and grandparents' evaluations of an intergenerational perinatal bereavement program. $J$ Perinat Neonatal Nurs. 2011;25(1):77-85.

27. Büssing A, Waßermann U, Hvidt NC, Längler A, Thiel M. Spiritual needs of mothers with sick new born or premature infants-A cross sectional survey among German mothers. Women and Birth. 2018;31(2):e89-98.

28. Rahiminia E. Nursing Behaviors which Facilitate the Grief Work of Parents with Premature Infants in Neonatal Intensive Care Unit: A Comparison of Mothers and Fathers. Nurs Midwifery Stud. 2013;2(2):206-9.

29. Heinemann AB, Hellström-Westas L, Hedberg Nyqvist K. Factors affecting parents' presence with their extremely preterm infants in a neonatal intensive care room. Acta Paediatrica. 2013;102(7):695-702.

30. Mirghafourvand M, Ouladsahebmadarek E, Hosseini MB, Heidarabadi S, Asghari-Jafarabadi M, Hasanpour S. The effect of creating opportunities for parent empowerment program on parent's mental health: A systematic review. Iranian Journal of Pediatrics. 2017;27(2):e5704. [Persian]

31. Jafari Mianaei S, Alaei Karahroudi F, Rasouli M. Study of the impacts of rehabilitation program on mothers with premature hospitalized infants. Education \& Ethic In Nursing. 2012;1(1):2-37. [Persian]

32. Bowes S, Lowes L, Warner J, Gregory JW. Chronic sorrow in parents of children with type 1 diabetes. $J$ Adv Nurs. 2009;65(5):992-1000.

33. Doering LV, Dracup K, Moser D. Comparison of psychosocial adjustment of mothers and fathers of high-risk infants in the neonatal intensive care unit. Journal of Perinatology. 1999;19(2):132-7.

34. Valizadeh L, Zamanzadeh V, Rahiminia E. Comparison of anticipatory grief reaction between fathers and mothers of premature infants in neonatal intensive care unit. Scand J Caring Sci. 2013;27(4):921-6.

35. Zamanzadeh V, Valizadeh L, Rahiminia E, Ranjbar Kochaksaraie F. Anticipatory grief reactions in fathers of preterm infants hospitalized in neonatal intensive care unit. $J$ Caring Sci. 2013;2(1):83-8. [Persian]

36. Ionio C, Colombo C, Brazzoduro V, Mascheroni E, Confalonieri E, Castoldi F, Lista G. Mothers and fathers in NICU: The impact of preterm birth on parental distress. Eur J Psychol. 2016;12(4):604-21. 